\title{
Microcephaly-cleft palate-abnormal retinal pigmentation syndrome
}

INSERM

\section{Source}

INSERM. (1999). Orphanet: an online rare disease and orphan drug data base.

Microcephaly-cleft palate-abnormal retinal pigmentation syndrome. ORPHA:2521

Microcephaly-cleft palate-abnormal retinal pigmentation syndrome is a rare orofacial clefting syndrome characterized by microcephaly, cleft of the secondary palate and other variable abnormalities, including abnormal retinal pigmentation, facial dysmorphism with hypotelorism and maxillary hypoplasia. Goiter, camptodactyly, abnormal dermatoglyphics and mild intellectual disability may also be associated. There have been no further descriptions in the literature since 1983. 